\title{
Compared to wireless deployment in areas with different environments
}

\author{
Inaam Abbas Hieder \\ Department of IT, College of Medicine, University of Baghdad, Iraq
}

\begin{tabular}{|c|c|}
\hline Article Info & ABSTRACT \\
\hline Article history: & \multirow{7}{*}{$\begin{array}{l}\text { In the mobile phone system, it is highly desirable to estimate the loss of the } \\
\text { track not only to improve performance but also to achieve an accurate } \\
\text { estimate of financial feasibility; the inaccurate estimate of track loss either } \\
\text { leads to performance degradation or increased cost. Various models have } \\
\text { been introduced to accurately estimate the path loss. One of these models is } \\
\text { the Okomura / Hata model, which is recommended for estimating path loss in } \\
\text { cellular systems that use micro cells. This system is suitable for use in a } \\
\text { variety of environments. This study examines the comparison of path loss } \\
\text { models for statistical analysis derived from experimental data collected in } \\
\text { urban and suburban areas at frequencies of } 150-1500 \text { MHz's. The results of } \\
\text { the measurements were used to develop path loss models in urban and } \\
\text { suburban areas. The results showed that Pathloss increases in urban areas } \\
\text { respectively. } \\
\text { Copyright } @ 2019 \text { Institute of Advanced Engineering and Science. } \\
\text { All rights reserved. }\end{array}$} \\
\hline Received Jul 12, 2018 & \\
\hline Revised Oct 16, 2018 & \\
\hline Accepted Dec 3, 2018 & \\
\hline Keywords: & \\
\hline \multirow[t]{2}{*}{$\begin{array}{l}\text { Free space propagation model } \\
\text { Okumura/hata model }\end{array}$} & \\
\hline & \\
\hline \multicolumn{2}{|l|}{ Corresponding Author: } \\
\hline $\begin{array}{l}\text { Inaam Abbas Hieder, } \\
\text { Department of IT, } \\
\text { College of Medicine, Universi } \\
\text { Email: inaam62@gmail.com }\end{array}$ & aghdad, Iraq. \\
\hline
\end{tabular}

\section{INTRODUCTION}

Path loss is the deterioration of the received power of electromagnetic signal when spread through space. Path loss results in many effects such as path loss in free space, refraction, reflection, reflection, and coupling. The loss depends on the path of several factors, such as propagation pattern, environments, and the distance between the transmitter and receiver, height and location of antennas. Also, it may take the signal from the transmitting antenna several paths (multiple paths) to reach the side of the future, which increase or decrease the received signal level depending on the construction or destructive interference multiple tracks waves [1]-[7].

The path loss is inevitable in assessing the quality of the network and its capabilities in terms of effective and reliable for the growth of mobile communications coverage [2]. This paper focuses on the results of the experimental and statistical analysis using the $150-1500 \mathrm{MHz}$ hata model, which uses the most widely used models in the network deployment planning. It is also very useful in conducting interference studies during deployments. Many experiments have been conducted in the urban city and suburban to verify the applicability of the appropriate path loss models in mobile communications. This research aims to improve the quality of wireless service in urban and suburban areas.

Path loss models can be classified according to distance of the separation either as long-distance predicted models for total cells or short-distance prediction models for small cells. Pico cells (cells that cover part of a building and extend mainly from (30 to 100 meters) can be included in short-distance prediction models. Internal forecasting models were introduced to estimate path loss in this case. Figure 1 shows a schematic classification of path loss models. They began with the simplest model of loss of path on the line of sight; also referred to as the free-space propagation model. In the free space propagation model, there are no obstructions due to ground surface or other obstructions during propagation. Among these models is the 
Okumura / Hata model, which is suitable for use in a variety of nonlinear environments (typical urban and environmental environments, traditional and rural) [10].

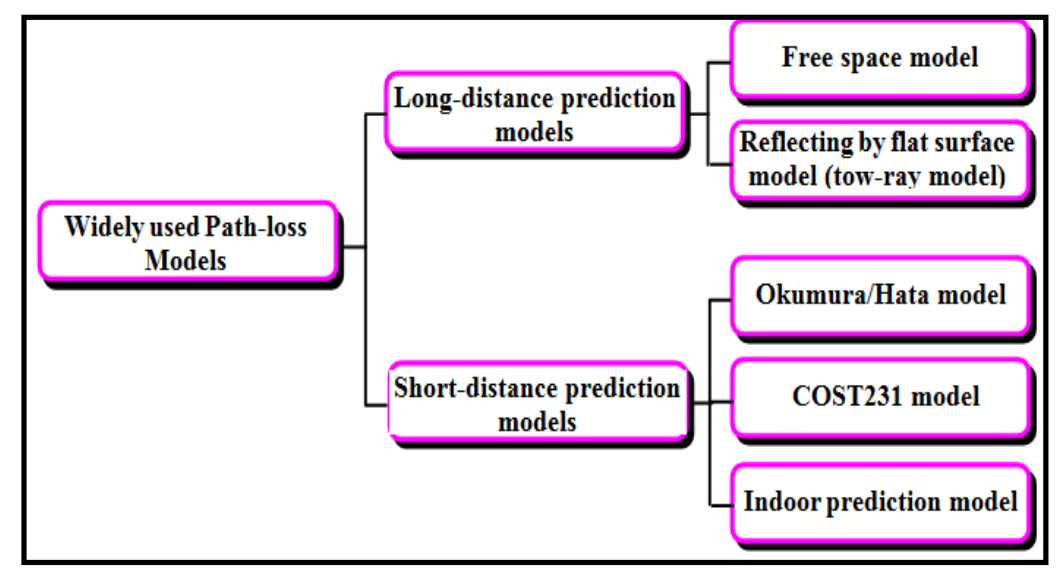

Figure 1. Shows a schematic classification of path loss models

\section{FREE SPACE PROPAGATION MODEL}

At a given separation between a transmitter and receiver there is a loss in signal strength that is due to the free space path loss. In addition to this there is some additional loss suffered by the signal if it encounters any obstructions before reaching the receiver. The physical phenomena that primarily degrade the signal are reflection, diffraction, and scattering. If the free space model assumes that there are no obstructions in the signal path and that the signal travels in a single continuous medium, under these conditions an equation can be derived for the received signal power at a given distance from the transmitter. This equation is known as the first transmission formula [3], [4].

$$
P_{r}(d)=\frac{P_{t} G_{r} G_{t} \lambda^{2}}{(4 \pi d)^{2} L}
$$

Where $(\operatorname{Pr}(\mathrm{d}))$ is the received power, (d) is the distance between $\mathrm{R}$ an $\mathrm{T}$ in meters, $\mathrm{Pt}$ is the transmitted power, $(\mathrm{Gt})$ and $(\mathrm{Gr})$ are the transmitter and receiver antenna gains, respectively $(\lambda)$ is the wavelength in meters, and (L) is a factor that is related to losses in the receive system.

The path loss of the system is the loss in signal strength from the transmitter to the receiver over a certain distance, this can be represented by:

$$
P_{L}(d)=\frac{P_{t}}{P_{r}(d)}
$$

Which can be written as:

$$
\bar{P}_{L}\left(d_{o}\right)=10 \log _{10}\left[\frac{\left(4 \pi d_{o} / \lambda\right)^{2} L}{G_{r} G_{t}}\right]
$$

It is convenient to measure the lost at a reference distance (do). In order to calculate path loss at any arbitrary distance, a ratio between the actual distance and reference distance is used as shown in the following:

$$
P_{r}(d)=P_{r}\left(d_{o}\right)\left(\frac{d}{d_{o}}\right)^{n}
$$


The path loss exponent, (n), in the above equation depended on the type of environment in which the signal is propagating. For practical purpose the value of (n) must be found for specific environment [5], [3], [6], [7]. Table 1 shows some measured value of (n) in different environment taken from [3].

Table 1. Path Loss Exponents for Different Environment

\begin{tabular}{cc}
\hline Environment & Path Loss Exponents, $\mathrm{n}$ \\
\hline Free Space & 2 \\
Urban Area Cellular Radio & $2.7-3.5$ \\
Shadowed Urban Area Cellular Radio & $3-5$ \\
In Building Line - Of-Sight & $1.6-1.8$ \\
Obstructed In Building & $4-6$ \\
Obstructed In Factories & $2-3$ \\
\hline
\end{tabular}

\section{HATA MODEL}

The model that formulated the Okumurae's observations into a simple mathematical model of frequency, antenna heights and pathloss exponent and (d) is the distance. Hata divided the prediction area into two set of terrain categories, suburban and urban area [7].

The Hata model is a widely used median path loss empirical model and suitable for frequency range of $150-1500 \mathrm{MHz}$ for distance from $1 \mathrm{~km}$ to $20 \mathrm{~km}$. It specifies the Base Station antenna height to be from $30 \mathrm{~m}$ and Mobile Station height from $3 \mathrm{~m}$ and room for correction factors addition. The Equations 5-8 represent the urban, suburban and open area Pathloss Equations [8]. Table 2 show the range of parameters for which okumura/Hata model

\subsection{Hata model for urban area}

In wireless s communication, the Hata model for urban areas, also known as the Hata model for being a developed version of the Okumura model, is the most widely used radio frequency propagation model for predicting the behavior of cellular transmissions in built up areas. This model incorporates the graphical information from Okumura model and develops it further to realize the effects of diffraction, reflection and scattering caused by city structures. This model also has two more varieties for transmission in suburban areas and open areas. Hata model predicts the total path loss along a link of terrestrial microwave or other type of cellular communications [9]. The Hata model for urban areas is formulated as following:

$$
\mathrm{Lu}=69.55+26.16 \log 10 \mathrm{f}-13.82 \log 10 \mathrm{hB}-\mathrm{CH}+[44.9-6.55 \log 10 \mathrm{hB}] \log 10 \mathrm{~d}
$$

For small or medium sized city:

$$
\mathrm{C}_{\mathrm{H}}=0.8+\left(1.1 \log _{10} \mathrm{f}-0.7\right) \mathrm{hM}-1.56 \log 10 \mathrm{f}
$$

For large cities:

$$
\left.\begin{array}{l}
\mathrm{CH}=8.29(\log 10(1.54 \mathrm{hM})) 2-1.1, \text { if } 150 \leq \mathrm{f} \leq 200 \\
\mathrm{CH}=3.2(\log 10(11.75 \mathrm{hM})) 2-4.97, \text { if } 200<\mathrm{f} \leq 1500
\end{array}\right\}
$$

Where:

$L u=$ Path loss in urban areas: decibel $(\mathrm{dB})$

$h B=$ Height of base station antenna: meter $(\mathrm{m})$

$\mathrm{h}_{\mathrm{M}}=$ Height of mobile station antenna : meter $(\mathrm{m})$

$f=$ Frequency of transmission: Megahertz $(\mathrm{MHz})$.

$\mathrm{CH}=$ Antenna height correction f a c t o $\mathrm{r}$

$d=$ Distance between the base and mobile stations: kilometer $(\mathrm{km})$

\subsection{HATA model for suburban area}

The Hata model for suburban environments is applicable to the transmissions just out of the cities and on rural areas where man-made structures are there but not so high and dense as in the cities. To be more precise, this model is suitable where buildings exist, but the mobile station does not have a significant variation of its height. 
It is formulated as [9]:

$\left\{\right.$ displaystyle L_ $\left.\{\mathrm{SU}\} \backslash ;=\mid ; \mathrm{L}_{-}\{\mathrm{U}\} \backslash ;->; 2\left\{\operatorname{lbig}(\} \backslash \log \_\{10\}\{\mid \operatorname{frac}\{\mathrm{f}\}\{28\}\}\{\operatorname{lbig})\right\}^{\wedge}\{2\} \backslash ;->; 5.4\right\} \mathrm{LSU}=\mathrm{LU}-2(\log 10 \mathrm{f} / 28)^{\wedge} 2-5.4(8)$

Where:

$L_{S U}=$ Path loss in suburban areas: decibel $(\mathrm{dB})$

$L_{U}=$ Average path loss from the small city version of the model: decibel (dB)

$f=$ Frequency of transmission $\mathrm{t}$ megahertz $(\mathrm{MHz})$.

Table 2. The Range of Parameters for Which Okumura/Hata model

\begin{tabular}{lcc}
\hline & Minimum value & Maximum value \\
\hline Carrier frequency $f_{c}(\mathrm{MHz})$ & 150 & 1500 \\
Base station height $h b(\mathrm{~m})$ & 30 & 200 \\
Mobile station height $h_{m}(\mathrm{~m})$ & 1 & 10 \\
distance $d(\mathrm{Km})$ & 1 & 20 \\
\hline
\end{tabular}

\section{SIMULATION METHOD}

The program is used to simulate the receipt of paper MATLAB, data is entered in the program and stored in the file, and information such as antenna height (base station) and antenna (mobile station), the distance, the power of the transmitter, when you run the simulation in the frequency bands (150-1500) $\mathrm{MHz}$ frequency is used in each Free Space Loss and model Hata mentioned frequency, it is considered two types of terrain, urban, suburban and loss account in the transfer of power.

\section{PERFORMANCE WITH FREE SPACE LOSS}

The performance of free space path loss has been measured using Equation 1. It is drawn with the distance in $(\mathrm{Km})$ as shown in Figure 2. It is clear from this figure that as the distance increases the receiver power $\mathrm{dB}$ increases too. This figure considers different values of transmitter power $(\mathrm{Pt}=3,5$, and 7$) \mathrm{W}$ and base station antenna height (30-200) $\mathrm{m}$.

Figure 3 loss Receiver power in the free space model depends on the HB $(50,100.150) \mathrm{m}$ and $\mathrm{d}$. In this figure that as the distance and base station antenna height increases $(50,100,150) \mathrm{m}$ the receiver power $\mathrm{dB}$ increases too.

Figure 4 loss Receiver power $\mathrm{dB}$ in the free space model depends on the $\mathrm{HB}(100 \mathrm{~m})$ and $\mathrm{Pt}$ $(3,5$, and 7$) \mathrm{W}$. In this figure that as the distance and transmitter power the receiver power $\mathrm{dB}$ increases too.

Figure 5 loss Mobile antenna height $\mathrm{dB}$ depends on frequency $(500,1000$, and 1500) $\mathrm{MHz}$ and distains $(10,15$, and 20$) \mathrm{km}$. In this figure that as the frequency and distance the loss mobile antenna height $\mathrm{dB}$ (loss Receiver power dB )increases too.

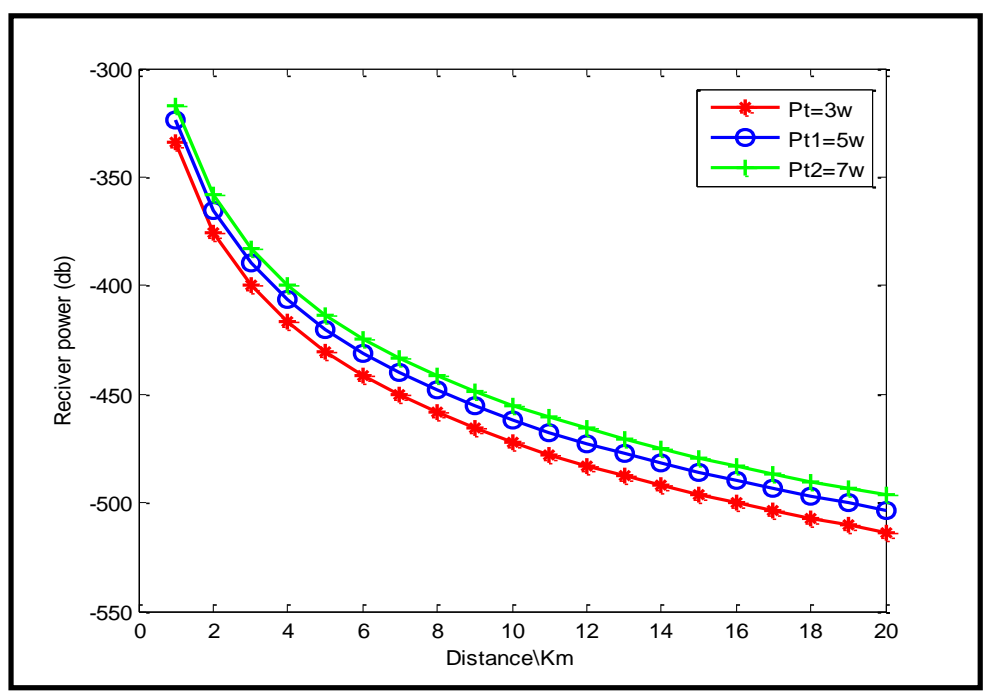

Figure 2. Loss receiver power depends Pt and d 


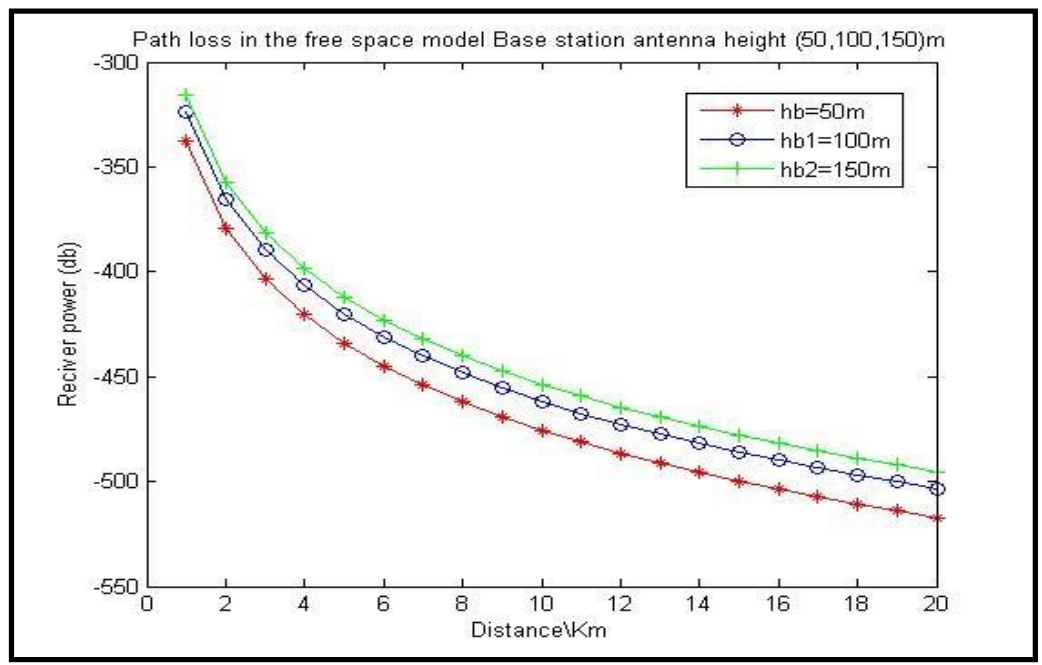

Figure 3. Loss receiver power in the free space model depends HB and d

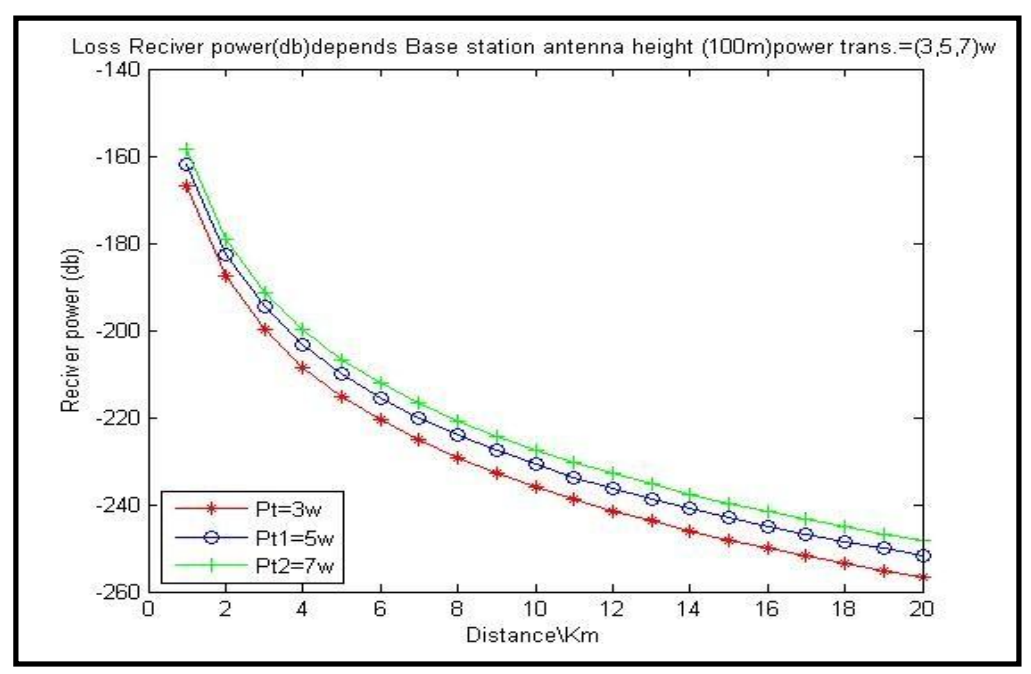

Figure 4. Loss receiver power $\mathrm{dB}$ depends on the $\mathrm{HB}(100 \mathrm{~m})$ and $\mathrm{Pt}$

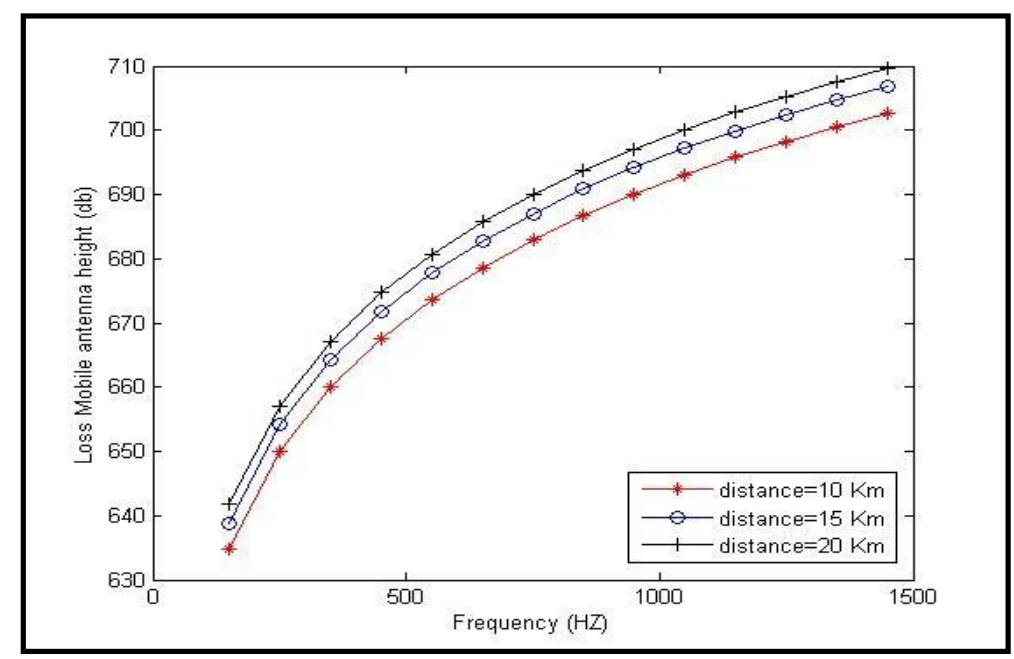

Figure 5. Loss mobile antenna height $\mathrm{dB}$ depends on frequency and $\mathrm{d}$ 
Figure 6 shows on mobile station antenna height $(\mathrm{Hm}=1-10) \mathrm{m}$ and power transmitted $(5 \mathrm{~W})$. It shows the effect of the mobile station antenna height $(\mathrm{Hm})$ with aspect receiver power. In this figure that as the mobile station antenna height and power transmitted watt increases the loss Receiver power dB decrease too.

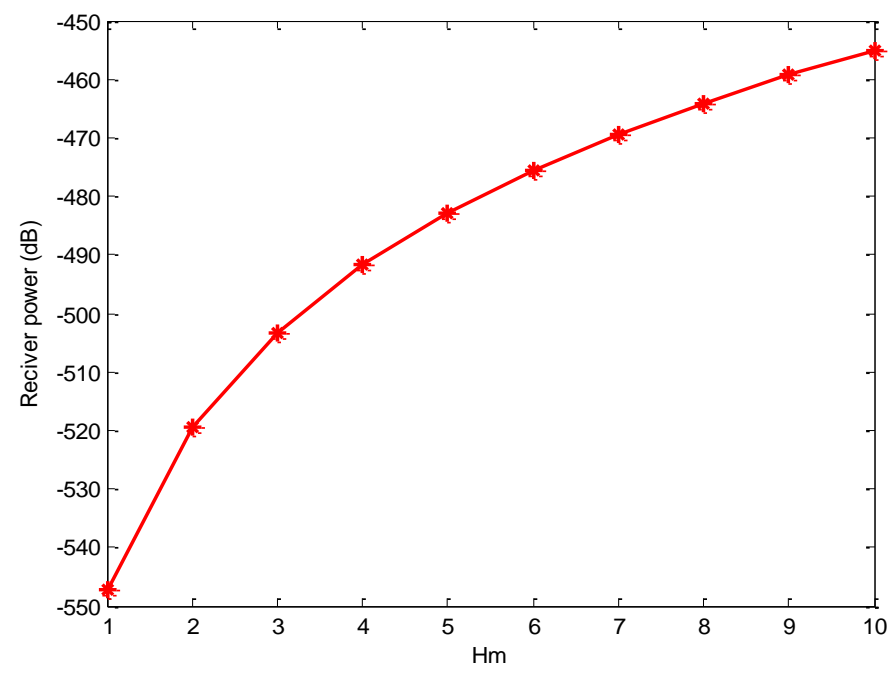

Figure 6. Loss receiver power $\mathrm{dB}$ depends $\mathrm{Hm}$ and $\mathrm{Pt}$

\section{PERFORMANCE LOSS HATA MODEL}

Figure 7 and Figure 8 represent the results of estimating path loss using a model in Hata two different areas, namely the urban area and the suburb area and estimated results measured at a frequency of (150 -500-1500) MHz.

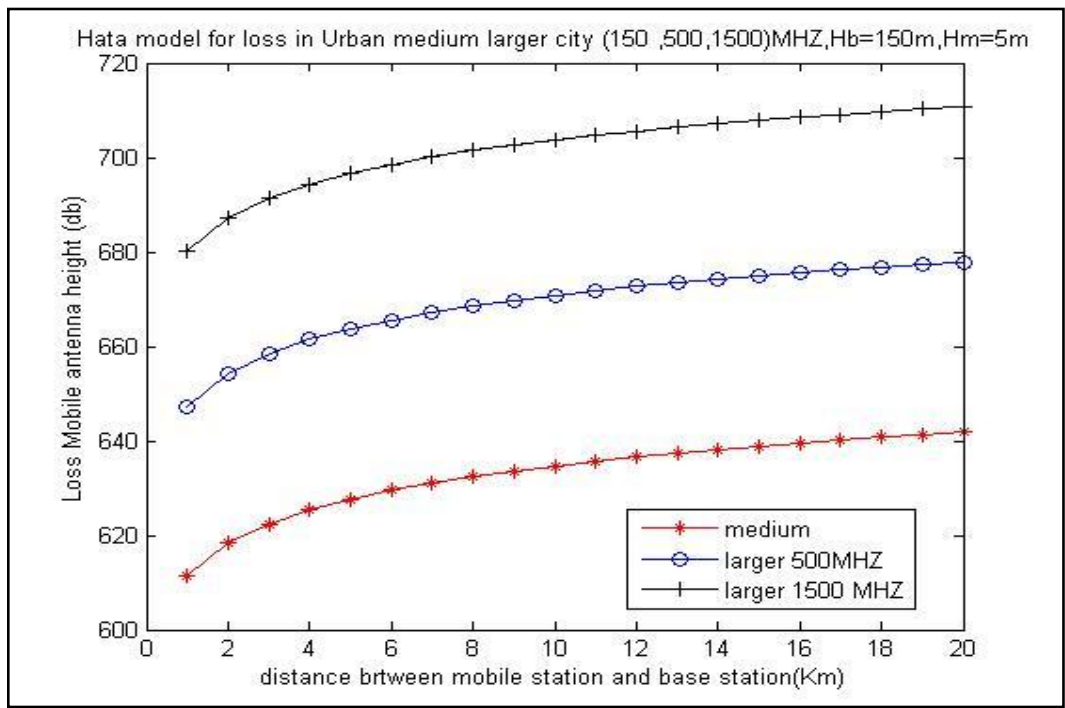

Figure 7. Hata model for loss in urban frequency and distance

Finger (7) path loss using Hata model the urban area when increases frequency $\mathrm{MHz}$ and distance $\mathrm{Km}$ the loss Receiver power dB increases too. 
Finger (8) path loss using Hata model the suburban area when increases frequency $\mathrm{MHz}$ and distance $\mathrm{Km}$ the loss Receiver power $\mathrm{dB}$ increases too. In the urban areas, the rise of the antenna height of the transmitters and receivers and the frequency of the transmitter. For the purpose of obtaining the best signal at the Receiver and decrease loss Receiver power $\mathrm{dB}$.

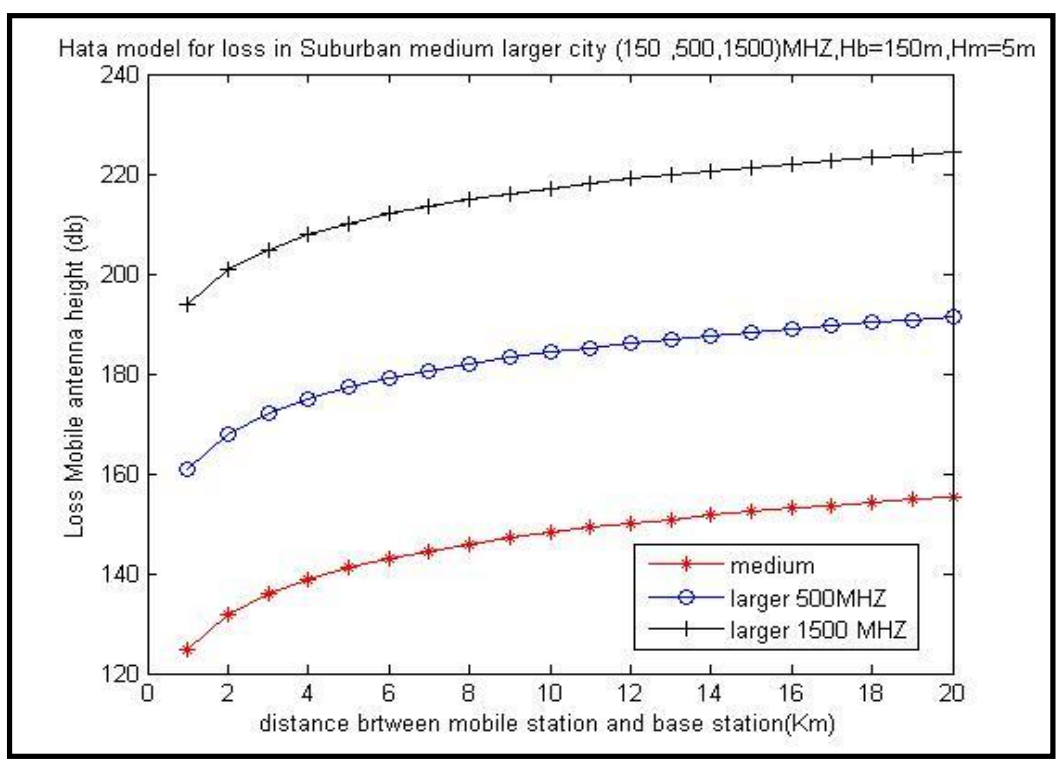

Figure 8. Hata model for loss in Suburban frequency and distance

\section{CONCLUSIONS}

This research, are where compared to the path loss models using different height antenna transmitter and change the power transmitter, distance, frequency and impact on the energy received. Comparison of path loss between urban and suburban frequency transmitter (150-1500) MHz Using the Hata model, the best fit for the suburban area.

In the urban areas, the rise of the antenna height of the transmitters and receivers and the frequency of the transmitter. For the purpose of obtaining the best signal at the Receiver and decrease loss Receiver power $\mathrm{dB}$.

\section{REFERENCES}

[1] Ubom EA, Idigo VE, Azubogu ACO, Ohaneme CO, “Alumona TL (2011) path loss characterization of Wireless propagation for South-south region of Nigeria," International Journal of computer Theory and Engineering 3: 360-364.

[2] Nwalozie Gerald C, Ufoaroh SU, Ezeagwu CO, "Ejiofor AC (2014) Path loss on Prediction for GSM Mobile networks for urban Region of Aba," South-East Nigeria International Journal of computer Science and Mobile computing 3:267-281.

[3] T. Rappaport, "Wireless Communications, Principles and Practice," 2nd ed., Printice-Hall Inc., 2002.

[4] J. Yun, "A Daptive Resource Allocation for D-TDD Systems in Wireless Multimedia Networks," Ph. D. Thesis, University of Pennsylvania State, May 2004.

[5] K. Wesolowski, "Mobile Communication System," University of Technology, Poland, 2002.

[6] T. Keith, "Design and Implementation of Pilot signal Scanning Receiver for CDMA Persond Communication services system," MSc. Thesis, University of Institate, 1998.

[7] Nnamani Kelvin N., and Alumona TL, "Path Loss Prediction of Wireless Mobile Communication for Urban Areas of Imo State, South-East Region of Nigeria at 910 MHz," Sensor Network Data Commination 2015, 4:1.

[8] Gupta V., Sharma, S. C. and Bansal, M. C. (2009), "Fringe Area Path Loss Correction Factor for Wireless Communication," International Journal of Recent Trends in Engineering, Vol. 1, No. 2.

[9] https://en.wikipedia.org/wiki/Hata_model.

[10] Ibrahim Mohamed, "Path-Loss Estimation for Wireless Cellular Networks Using Okumura/Hata Model," Science Journal of Circuits, Systems and Signal Processing, 2018; 7(1): 20-27. 